\title{
Feasibility of Monitoring Rock Fall in Yosemite Valley Using Seismic Methods
}

S.C. Myers, D. Rock, K. Mayeda

\section{March 2, 2000}

\section{Lawrence}

Livermore

National

Laboratory 


\section{DISCLAIMER}

This document was prepared as an account of work sponsored by an agency of the United States Government. Neither the United States Government nor the University of California nor any of their employees, makes any warranty, express or implied, or assumes any legal liability or responsibility for the accuracy, completeness, or usefulness of any information, apparatus, product, or process disclosed, or represents that its use would not infringe privately owned rights. Reference herein to any specific commercial product, process, or service by trade name, trademark, manufacturer, or otherwise, does not necessarily constitute or imply its endorsement, recommendation, or favoring by the United States Government or the University of California. The views and opinions of authors expressed herein do not necessarily state or reflect those of the United States Government or the University of California, and shall not be used for advertising or product endorsement purposes.

This work was performed under the auspices of the U. S. Department of Energy by the University of California, Lawrence Livermore National Laboratory under Contract No. W-7405-Eng-48.

This report has been reproduced directly from the best available copy.

Available electronically at http://www.doe.gov/bridge

Available for a processing fee to U.S. Department of Energy

and its contractors in paper from

U.S. Department of Energy

Office of Scientific and Technical Information

P.O. Box 62

Oak Ridge, TN 37831-0062

Telephone: (865) 576-8401

Facsimile: (865) 576-5728

E-mail: reports@adonis.osti.gov

Available for the sale to the public from

U.S. Department of Commerce

National Technical Information Service 5285 Port Royal Road

Springfield, VA 22161

Telephone: (800) 553-6847

Facsimile: (703) 605-6900

E-mail: orders@ntis.fedworld.gov

Online ordering: http://www.ntis.gov/ordering.htm

OR

Lawrence Livermore National Laboratory

Technical Information Department's Digital Library

http://www.llnl.gov/tid/Library.html 
Feasibility of Monitoring Rock Fall in Yosemite Valley Using Seismic Methods

Stephen C. Myers, Don Rock, and Kevin Mayeda

Lawrence Livermore National Laboratory

Geophysics and Global Security Division, L-205

Livermore, California 94550 


\section{Summary}

Public awareness of rock-fall hazard in Yosemite Valley has heightened after events in 1996 and 1999. Reports of audible blasts prior to rock-fall events suggest that rock cracking may in some instances precede the detachment a block from the cliff face. Seismic methods may be used to detect and locate small, inaudible rock cracking events, resulting in a catalog that outlines active areas and quantifies the level of activity.

In order to test the feasibility of monitoring rock-fall activity with seismic methods, the Test Yosemite Rock-Fall Network (TYRN) was operated in the late summer and fall of 1999. The TYRN included five stations in the vicinity of the 1999 rock fall events: 2 stations at the base of the cliff and 3 above.

Location of events depends on an estimate of seismic-wave velocity. During the TYRN deployment, a septic tank near Glacier Point was demolished, allowing the velocity of seismic P-waves to be calibrated. P-wave velocity was found to be about $5.68 \mathrm{~km} / \mathrm{s}$. Recordings of the explosion also allow assessment of arrival time precision, which controls the precision of seismic locations. Explosion recordings suggest that P-waves can be picked with a precision of about 0.005 seconds, suggesting that a seismic monitoring system would be able to locate events on the cliff face with sufficient precision to be useful in rock-fall monitoring.

We used the amplitude of seismic noise recorded on the test network to determine the smallest event likely to be detected by the TYRN. An event with equivalent earthquake magnitude of -2.6 would be detectable at a sufficient number of stations to afford a location. This magnitude is equivalent to about 1.8 centimeters of slip on a surface with area of 1 square meter. Smaller displacements would be detectable for larger slip surfaces.

The vast majority of events recorded on the TYRN were from the Mammoth Lakes region. About 5 to 6 events from the Mammoth Lakes area were recorded per day, but considerably more events were recorded on active days. A number of "suspect" events were also recorded by the TRYN. We term these events suspect, because the seismic waveforms have the characteristics that we expect from an event originating on the rock face. However, these events were not recorded at enough stations to determine a location. Based on the calculations for the minimum detectable event, we believe that the suspect events are tiny.

We conclude that seismic monitoring of rock fall activity is Yosemite theoretically feasible, but the detection of rock-fall-related events has not been verified. The lack of verifiable events occurring on the cliff face during the operation of the TYRN may be due to the warm, dry weather during the experiment. During the experiment there were no reports of rock fall or audible events. A deployment during the winter and spring, when snow melt and precipitation tend to increase activity, may produce more definitive results. 


\section{Introduction}

Rock-fall events in Yosemite Valley are inevitable due to the steep topography and natural weathering processes that continually loosen blocks from the adjoining rock face. Twice within the last four years deadly rock-fall events have occurred within Yosemite Valley. In July of 1996, a rock fall occurred near Happy Isles that killed 1 person and severely injured several others. The 1996 event consisted of two tabular blocks: one about 50 feet in diameter, and the other about 100 feet by 25 feet (Wieczorek et al., 2000, Uhrhammer, 1996). The air blast from this event was sufficiently strong to uproot mature trees and damage nearby structures. Again in the spring of this year (1999) a series of rock falls occurred, killing one person and injuring two others. The source area for the recent rock fall was above Curry Village, and the source dimensions were about 50 feet by 30 feet (Wieczorek and Snyder, 1999). Although the recent events were significantly smaller than the 1996 event, they directly threaten a significant number of park visitors and park infrastructure. Understandably, public concern about rock-fall hazard has heightened, warranting studies into effective ways to monitor rock-fall activity.

Rock fall activity is not new to Yosemite Valley, as outlined by Wieczorek et al., (1998). More than 400 rock falls have been documented in historic times, resulting in ten deaths. The volume of rock involved in individual events varies by many orders of magnitude, with documented events in approaching 1,000,000 cubic meters. Massive events pose obvious hazard to life and infrastructure, but more frequent, smaller events are also important to considered when assessing hazard. Rock fall hazard extends beyond the obvious danger of being struck or buried by falling rock. This point was illustrated in the 1996 event in which a fatality and other serious injuries resulted from the ensuing air blast and tree knock down. Additional hazard has frequently been realized upon impact of a block at the base of a cliff, where even a modest-sized rock can fragment into shrapnel-like shards traveling at hundreds of meters per second. Such shards can be lethal.

Occurrence of rock-fall events is often correlated with periods of heavy rain, snow melt and freeze thaw conditions (e.g. Wieczorek and Snyder, 1999). Hydrolic pore pressure and expansion during freezing can plausibly enhance crack formation and propagation, leading to the detachment of blocks from the cliff face. However, a definitive cause and effect relationship is not well established. Recent, first-hand accounts have given insight into precursory activity that may aid in real-time monitoring of rock-fall activity. Loud audible blasts (likened to the report of a shotgun) have been heard prior to rock falls in Yosemite Valley. Audible reports are particularly well documented throughout the series of events in 1999, and these blasts were correlated with the opening of cracks near the rock fall release point (J. Snyder, personal communication). Although the audible blasts are linked with rock cracking, they are not always followed by rock fall.

The audible blasts suggest that crack development can occur in discrete events. If significant cracking were identified prior to the detachment of the block, then increased, localized risk may be assessed. Locating the source of the cracking event is the fundamental challenge that would enable effective monitoring. Location of audible blasts 
is best accomplished with a network of microphones with accurate, synchronized clocks. With such a network, well-developed techniques can be used to determine source location from arrival times of sound waves at network stations. However, large rock cracking events that produce audible blasts are uncommon, so detection of rock cracking based on audible detection is likely to produce a prohibitively sparse catalog. Alternatively, tiny rock cracking events may be detected with nearby seismic sensors. The advantage of using seismic sensors is that small, presumably more frequent, events may be detected and located. Therefore, a catalog of events based on seismic detections is likely to better characterize the spatial and temporal pattern of rock cracking activity.

In this study we explore the feasibility of monitoring rock fall with seismic methods. We use observations from the TYRN to constrain quantitative estimates of both the smallest detectable event and the precision of seismic locations. We also use recordings from the TYRN and other studies to estimate the number and type of events that a monitoring system may expect to commonly observe.

\section{Seismic Deployment}

Between August 24, 1999 and November 10, 1999 LLNL, in cooperation with YNP, deployed 5 seismic stations in the vicinity of recent rock-fall activity (Figures 1 and 2). The deployment is termed the Test Yosemite Rock-Fall Network (TYRN). Two of the stations were at the base of the rock-face in the vicinity of Curry Village, and the remaining three stations were at the top of the rock face in the vicinity of Glacier Point (Figure 2). The naming convention for stations was based on station location: Lower East (LE) is the station at the cliff a base on the East side. Other stations are Lower West (LW), Upper East (UE), Upper West (UW), and Upper Sentinel (US). Criteria for locating stations emphasized 1) personnel safety (the project is in a known area of rock fall and dangerous cliffs), 2) sites where sensors can be placed on un-weathered granite, which enhances signal strength, 3) a station geometry that enhances the ability to locate events that are at the release point of recent rock falls, and 4) reasonable accessibility.

The station layout included a solar panel, battery, recording box, global positioning system (GPS) antenna, and a sensor. Ground motion was detected with $40 \mathrm{~Hz}$ geophones, and data were recorded using RefTek $72 \mathrm{~A}$ recorders. The GPS antenna provided station location and station clock synchronization.

Measurements of ground movement from the seismic sensors were spilt into two data streams. The first data stream was continuously recorded at a sample rate of 250 samples per second (SPS). The second data stream is digitized at 500 SPS, but only triggered "events" were saved to the disc. This approach provides a continuous record of ground motion and higher quality recordings in time windows that bracket distinct "events". On average, each station recorded about 48 Mbytes of data per day. Nearly 4 GigaBytes of data were collected by the TYRN. 


\section{Estimation of seismic velocity using a Fiducial Seismic Source}

Accurately known seismic velocity can be crucial to seismic location. Although a reasonable estimate of seismic velocity can be gleaned from the rock type and the degree of weathering, it is far more desirable to measure the velocity directly. With seismic velocity established, location of events becomes more accurate and reliable.

On October 21, 1999, a septic tank about 50m south of station GPUE was demolished with explosives. The explosive shot coupled sufficiently with the ground to produce seismic waves that where observed at all of the operating station of the TYRN. Despite having received a new battery the day prior to the explosion, station GPLW was not operating during the shot due to low battery voltage.

The operating stations obtained clear recordings of the shot. Because the velocity of seismic waves in crystalline rock is about ten times the velocity of sound waves, the seismic P-wave is the first recorded movement at the stations. This allows for accurate picks of P-wave arrivals due to small pre-arrival noise. Figure 3 shows the first few tenths of a second of the seismic recordings and the picked times for P-wave arrivals. We estimate that the picked times have a variance of about 0.005 seconds based on signal to noise estimates and the impulsiveness of the signal.

An optimal velocity is estimated by simultaneously solving the following system of equations:

$$
\frac{d_{i}}{V_{p}}+t_{o}=t_{i}
$$

The subscript $i$ counts each station; $d_{i}$ is the shot-station distance; $t_{i}$ is the observed arrival time; $t_{0}$ is the shot detonation time; and $\mathrm{Vp}$ is the P-wave velocity. Neither the shot detonation time nor the P-wave velocity are known, and these two parameters are determined in a least-squares optimization. We make the necessary assumption that $\mathrm{Vp}$ is constant throughout the rock mass. Considerably more data would be necessary to resolve spatial variability of the velocity distribution.

The optimal velocity for the observed station locations and arrival times is $5.685 \mathrm{~km} / \mathrm{s}$, which is within the expected range for crystalline rock at the surface. In addition to determining the optimal velocity, we also use a Monte Carlo technique to determine a rigorous uncertainty bound. The Monte Carlo technique with a priori model uncertainty is employed, because a more conventional F-statistic (fit to the data) is likely to result in optimistically small error bounds for such a small data set (the problem is barely over determined). The Monte Carlo analysis involved 10,000 realizations in which each arrival time and station location was perturbed from its mean. The distribution of each parameter was assumed to be Gaussian. Three variance estimates were tested for the arrival times $(0.01,0.005,0.002$ seconds). Only, two variance estimates where tested for the station locations $(10 \mathrm{~m}$ and $0 \mathrm{~m})$; because, uncertainty in station location was found to 
have negligible influence on the velocity estimate compared to arrival uncertainty (Figure 4). If a conservative estimate of arrival uncertainty is used $(0.01 \mathrm{sec})$, then the standard deviation of the estimated velocity is about $0.5 \mathrm{~km} / \mathrm{s}$. If an optimistic estimate of arrival uncertainty is used $(0.002 \mathrm{sec})$, then the standard deviation of the velocity estimate is about $0.1 \mathrm{~km} / \mathrm{s}$. We prefer an intermediate arrival uncertainty of $0.005 \mathrm{sec}$, resulting in a standard deviation of the velocity estimate of about $0.2 \mathrm{~km} / \mathrm{s}$. This degree is of uncertainty is high, but unavoidable due to the high velocity and short distances. It should be noted that record logs for each station were checked to insure that the station clocks were synchronized with GPS time. For each of the stations, maximum variation between the GPS and station time was 0.0005 seconds.

Direct S-waves were not observed. However, a large short period secondary phase is identified as a surface wave with a group velocity of approximately $3.0 \mathrm{~km} / \mathrm{s}$. Although explosion sources can produce $S$-waves in some instances, significant $S$-waves are unusual for above-the-ground shots like this one. This is unfortunate because rock cracking associated with rock fall should produce significant $S$-waves, which could be useful for location. Fortunately, S-wave velocity can be estimated using the measured Pwave velocity. $\mathrm{Vp} / \mathrm{Vs}$ in crustal/crystalline rocks is relative constant, with a value of 1.73. Assuming that $\mathrm{Vp} / \mathrm{Vs}=1.73, \mathrm{Vs}$ in the Glacier Point area is estimated to be 3.286 $\mathrm{km} / \mathrm{s}$. Both the Vp and Vs estimates are within the normal range for unweathered crystalline rock near the earth's surface.

\section{Estimation of location accuracy for rock-fall-related events recorded on the TYRN}

In order to assess the feasibility of using seismic methods to monitor rock-fall activity, a thorough analysis of location capability is required. Without confidence in the location of events, seismic monitoring would be of little utility.

One test of location accuracy is to relocate the fiducial shot that was used to calibrate seismic velocity. We conducted this test and reproduced the known location to within about 10 meters; however, this test is circular because we used the known location to calibrate velocity. Also, accurate locations are usually obtained when the source is close to one of the stations, as it is in the case for the fiducial shot.

A realistic test of location precision can be conducted by simulating seismic data and noise conditions. In this case, we use a fictitious (synthetic) event near the release point of the 1999 rock fall events. The travel-times of seismic waves from the synthetic event are then calculated to each of the stations. Random noise is added to the synthetic arrivals, and a location is determined in the same way that a real event would be determined. By repeating this process, and adding new realizations of random noise each time, the precision of the location due to random uncertainty in the arrival times is assessed. Figure 5a shows the results of this process for three different noise distributions: 0.01 second variance, 0.005 second variance, and 0.002 variance. These three variance levels represent conservative, intermediate, and optimistic noise levels, respectively. Even with noisy data ( 0.01 second variance) the location distribution would be "tight" enough to be useful in rock fall monitoring. Note that in this location 
algorithm we did not constrain the location to be physically realistic; events above the ground surface are permitted (Right panel of Figure 5a). Location precision could be significantly improved by constraining events to occur on the rock face (simulated in the left panel of Figure 5a).

Although velocity is measured with a fiducial source, velocity is not known exactly. Therefore, we tested the location accuracy that results from misassigning the velocity. To do this, we generated synthetic data using a velocity of $5.685 \mathrm{~km} / \mathrm{s}$ and relocated events using a velocity of $5.385 \mathrm{~km} / \mathrm{s}$. This degree of error is meant to represent a reasonable deviation from the velocity estimated using the fiducial source (Figure 5b). We found that this degree of error in velocity did not cause significant loss of location accuracy. It should be noted, however, that event location out side the bounds of the network will be significantly effected by velocity inaccuracies.

\section{Estimated Detection of Rock Cracking Events}

At the source-receiver distances of concern in this study (often less than $1 \mathrm{~km}$ ), complex wave propagation effects can be important to describing the seismic arrivals. However, by limiting the discussion to the smallest events we can assume that only far-field wave propagation effects are important. Additionally, we only consider P-wave (first) arrival detection. S-wave detection may be important, but analysis of $\mathrm{P}$-waves alone will provide a "ballpark" estimate of detection capability.

Detection of a seismic signal depends primarily on the follow parameters:

1) The "size" (energy) of the seismic source

2) The source-receiver distance

3) Efficiency of wave propagation in the rock

4) Sensitivity of the seismic sensor

5) Seismic noise level

For far-field $\mathrm{P}$-waves propagating spherically from a point source, the amplitude is given by:

$$
U_{p}(r, t)=\frac{1}{4 \pi \rho r V_{p}^{3}} R^{p} \dot{M}\left(t-\frac{r}{V_{p}}\right) \exp \left(\frac{\pi f t}{Q}\right)
$$

where $U$ is displacement at the sensor, $r$ is source-receiver distance, $t$ is time, $\rho$ is rock density, $V p$ is $\mathrm{P}$-wave velocity, $R^{p}$ is $\mathrm{P}$-wave radiation pattern, $M$ is the seismic moment rate ("size") of the source, $f$ is the frequency of the wave, and $Q$ is the seismic quality factor (accounts for attenuation). Equation [2] is a slight modification of a formula from Lay and Wallace (1995, p. 339). Measurements of seismic noise near $40 \mathrm{~Hz}$ from the TYRN give displacements of about $1 * 10^{-9}$ meter. If we assume that a signal must be twice the amplitude of the noise in order to be detected, then we can use equation [2] to estimate the smallest event detectable by the network. Performing this calculation gives a minimum moment of about $5.4 * 10^{9} \mathrm{~N}-\mathrm{m} / \mathrm{s} \quad(f=40, r=1000 \mathrm{~m}, Q=200, \mathrm{Vp}=5.6$ 
$\mathrm{km} / \mathrm{s}, \rho=2800, \mathrm{R}=0.44$, average radiation pattern, Boore and Boatright, $1984,40 \mathrm{~Hz}$ is assumed to be below the corner frequency of the event). The equivalent earthquake magnitude is about -2.6 .

Moment can be used to estimate the displacement of the dislocation.

$$
M=\mu A D
$$

Where $u$ is shear modulus, $A$ is the area of the dislocation surface and $D$ is the displacement of the dislocation. Assuming a nominal shear modulus of $3^{*} 10^{11} \mathrm{~kg} / \mathrm{ms}^{2}$, the product of $A D$ for the minimum detectable event is constrained to be about $1.8 \mathrm{~cm}$. So for a crack with an area of $1 \mathrm{~m}$, the displacement would be $1.8 \mathrm{~cm}(\sim 1 / 2 \mathrm{inch})$. Or for a crack behind a rectangular block 2 meters on a side, a displacement of about $0.45 \mathrm{~cm}$ is thought to be detectable.

\section{Observed Seismic Activity}

One goal of this study is to test the detectability of rock-fall-related events. We used two methods to scan for rock-fall related events. First, we grouped network triggers occurring within one second of one another. This technique yielded numerous events of similar character (an example is given in Figure 6). On average, roughly 5-6 of these events were recorded on the TYRN daily. Sometimes, tens of events were recorded in a single day. However, the difference between the S-wave and P-wave arrival ( $\mathrm{S}-\mathrm{P}$ time) is considerably longer than we would expect for an event on the cliff face. Using S-P time and the relative arrival times of P-waves at network stations, we estimate that these events are about $27 \mathrm{~km}$ away and roughly east of Yosemite Valley. These events are most likely associated with on-going activity near Mammoth Lakes.

Because the vast majority of triggered events during the TYRN deployment are non-rockfall-related events, careful analyst review of continuously recorded events was necessary. To review one day of data required two hours of analyst time. Therefore, approximately 160 hours of analyst time is required to carefully screen the data. Because that level of time commitment is beyond the means of this study, we choose to analyze the data at the beginning of the deployment - when rock-fall activity was waning from the June events, and a period between September 9, 1999 to October 10, 1999 - when GPS timing at all stations was operating reliably.

Detailed data review discovered a number of suspect events. However, these events are exceedingly small and they were recorded on only one (rarely two) stations, precluding event location. Figure 7 is an example of a suspect event; these events were not evenly distributed in time, but they occurred once or twice per day on average. The timing of Pwave and S-wave arrivals suggest that the event in Figure 7 could be within 1 or $2 \mathrm{~km}$ of the station, perhaps on the rock face. Furthermore, surface waves are evident (the lower frequency "tail" of the seismogram), suggesting that the event occurred near the surface. However, we are unable to definitively identify the source type without the benefit of a location. 
The rate of rock fall events can be estimated using Figure 1 of Wieczorek et al. (1998) (see URL http://greenwood.cr.usgs.gov/pub/open-file-reports/ofr-98-0467 for the figure). This figure presents a relationship for the observed number of rock-fall events (event frequency) as a function of rock volume between the years of 1900 and 1992 . The logarithm of event frequency increases roughly linearly as event volume decreases - a fractal relationship. The relationship between event frequency and landslide volume deviates from linearity for small events, but this is likely due to undetected events. If the linear relationship is valid (i.e. the relationship is not multifractal) then we would expect about 3000 events with a volume of 1 cubic meter over a 92 year period -- 32 events per year -2 or 3 events per month. Because the Wieczorek et al. (1998) frequency-volume relationship applies to all of Yosemite Valley, far fewer events are expected in the TYRN study area. However, our premise is that rock cracking occurs more frequently than actual rock-falls, and we may, therefore, expect a number of rock cracking events during the TYRN deployment.

Rock-fall and rock-cracking events are likely to be promoted by high fluid pore pressure and freeze-thaw processes (Wieczorek and Snyder, 1999). Therefore, rock-cracking and rock-fall events are expected to be more likely during winter and spring (wet and cold) seasons. The TYRN was deployed in hopes of recording rock-cracking events following rock falls earlier in the summer. Rock fall activity above Curry Village is reported as late as July 21, 1999 (Wieczorek and Snyder, 1999). However, the warm and dry weather of late summer and fall appears to have diminished activity, as no rock fall activity was reported during the operation of the TYRN (J. Snyder, personal communication).

\section{Conclusions}

Rock-fall in Yosemite poses an appreciable hazard to people and YNP infrastructure. One approach to mitigating this hazard is to monitor rock-cracking activity that is associated with rock fall. In order to assess the feasibility of monitoring rock-cracking activity with seismic methods, LLNL - in cooperation with YNP -- deployed a network of 5 seismic stations (the TYRN) (Figure 2). We used observations from this network to make quantitative estimates of detection and location of rock-cracking events on the cliffs of Yosemite.

The vast majority of seismic activity recorded on the TYRN originate from the Mammoth Lakes area (Figure 6). We observed 5 to 6 of these events per day, although many more events were detected on active days. We also observed 1 or 2 "suspect" events per day (Figure 7). For suspect events, wave form characteristics such as 1) the presence of Swaves, 2) the time difference between S-wave and P-wave arrivals, and 3) the low frequency surface wave following the events are in accord with expected seismogram characteristics for a rock-cracking event occurring on the cliff face. However, none of these events were recorded at enough stations to allow a precise location. Therefore, we do not claim to confidently identification these events. Additionally, events termed "suspect" are probably not all of the same source type. A variety of waveform 
characteristics met the suspect classification. Therefore, a rate of 1 or 2 events per day is an upper limit on any of the suspect subsets.

The seismic deployment provided important measurements of seismic velocity. During the deployment, a septic system was demolished using explosives. Seismic recordings of the explosion suggest that the P-wave velocity of the Glacier Point cliff is approximately $5.68 \mathrm{~km} / \mathrm{s}$ (Figure 4). Using the uncertainty in picking arrival times from the explosion, we estimate that seismic events occurring on the rock face can be located with sufficient precision to enable useful rock-fall-monitoring (Figure 5). Additionally, we used seismic noise measurements from the TYRN to estimate the smallest event that we may expect to detect. We expect to see events with an equivalent seismic magnitude of -2.6 at enough stations to afford a location. This equates to a crack with an area of 1 square meter moving $1.8 \mathrm{~cm}$.

A frequency-volume relationship (Wieczorek et al., 1998) predicts 2-3 small rock-fall events per month in Yosemite Valley. Because we expect more rock-cracking events than rock falls, the lack of clearly identified, rock-fall events during the TYRN deployment may be surprising. However, the lack of positively identified, rock-fallrelated events may be the result of monitoring during the late summer and fall when the weather was warm and dry. During the operation of the TYRN, neither rock falls nor audible blasts where reported. Ultimately, we conclude that rock-fall monitoring using seismic methods is theoretically feasible, but the lack of recorded events during the seismic deployment -- albeit during a period without reported rock-fall activity - prevents a definitive conclusion. More rock-fall events are expected in winter and spring, when rainfall and freeze-thaw action may enhance activity. The 1996 and 1999 rock-fall events occurred in late spring, and on the day of this writing (March 2, 2000), a large rock fall was reported in Yosemite Valley. Therefore, a seismic deployment from winter to summer may yield more definitive results.

\section{Acknowledgements}

We thank Jim Snyder at Yosemite National Park for making the TYRN deployment possible. Without Jim's efforts in the office as well as the field the TYRN deployment could not have been completed. We also acknowledge useful discussion on the subject of seismic source scaling with Bill Walter at LLNL. Gerry Wieczorek (USGS) provided useful reports and encouragement, and Jonathan Godt (USGS) provided the digital elevation map of Yosemite Valley. 


\section{References}

Lay, T. and T. Wallace (1995). Modern Global Seismology, Academic Press, 521 p.

Uhrhammer, R. (1996). Yosemite rock fall of July 10, 1996, Seismol. Res. Let., 67, 4748 .

Wieczorek, G., M. Morrissey, G. Iovine and J. Godt (1998). Rock-fall hazard in the Yosemite Valley, U.S. Geological Survey, open-file-report 98-467.

Wieczorek, G. and J. Snyder (1999). Rock falls from Glacier Point above Camp Curry, Yosemite National Park, California, U.S. Geological Survey, open-file-report 99-385.

Wieczorek, G., J. Snyder, J. Waitt, M. Morrissey, M. Uhrhammer, R. Harp, E. Norris, R. Bursik, M. Finewood (2000). The unusual air blast and dense sandy cloud triggered by the July 10, 1996 rock fall at Happy Isles, Yosemite National Park, California, Geol. Soc. Am. Bull., 112, 75-85. 


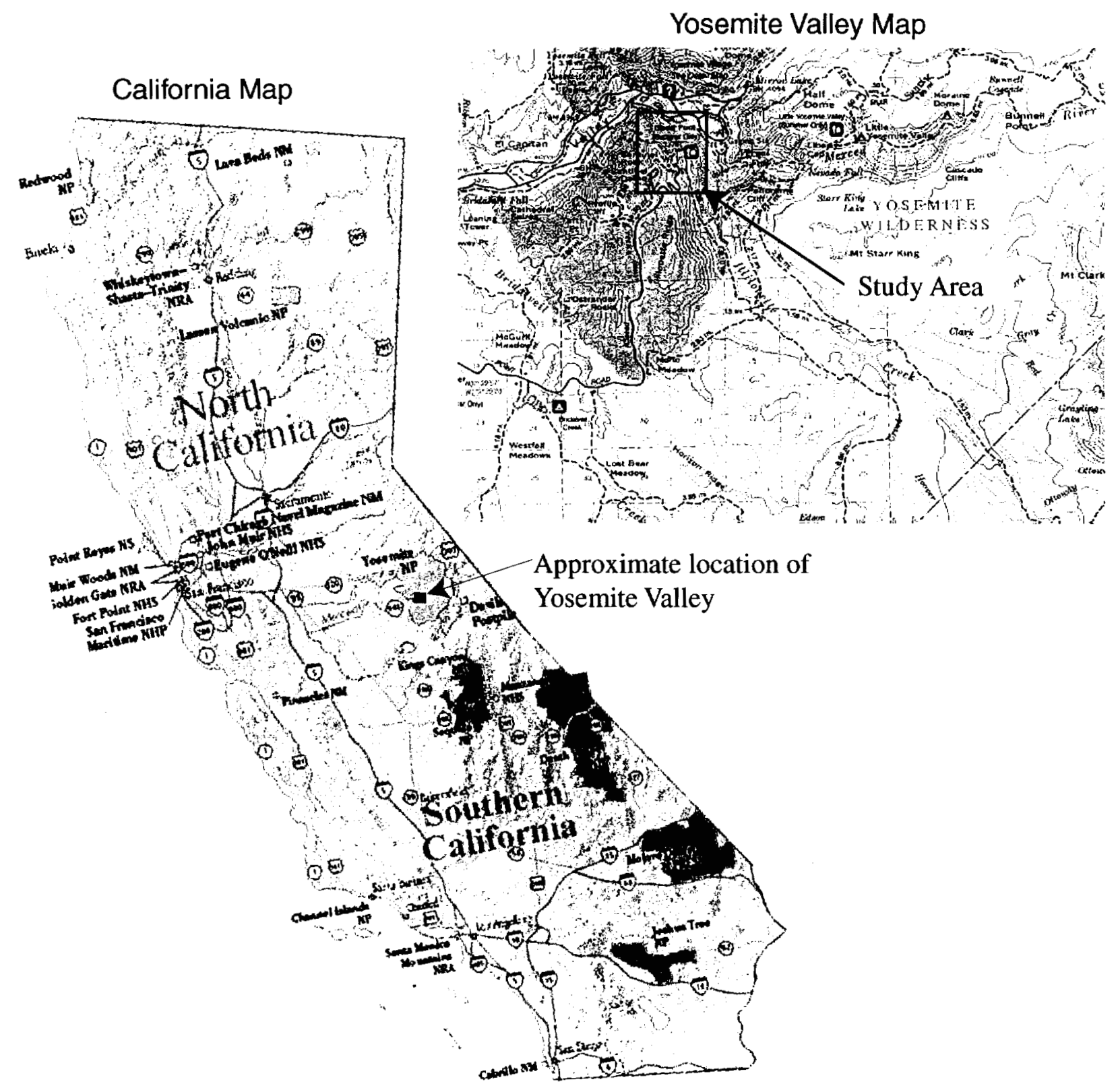

Figure 1. Regional and local maps of the study area. 

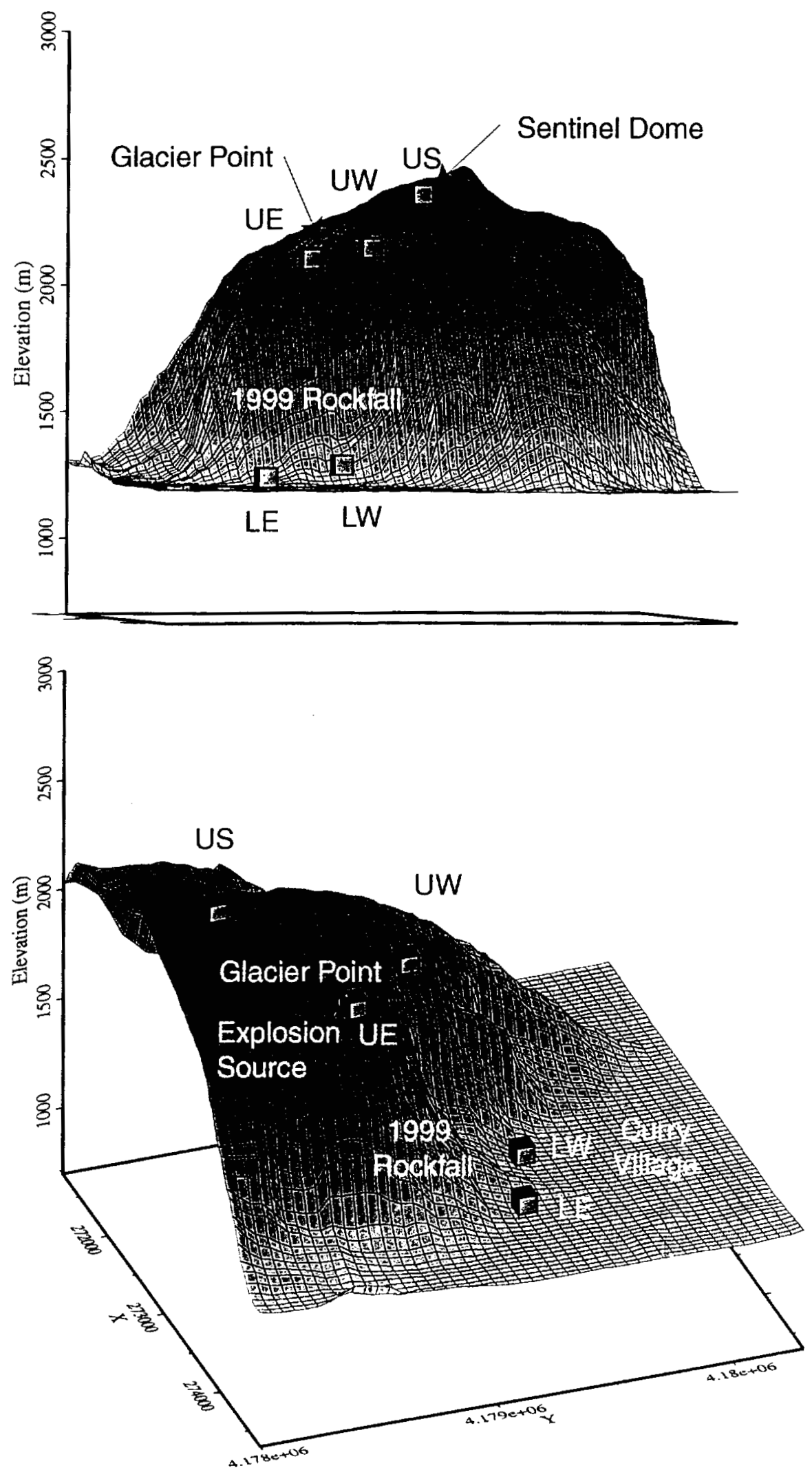

Figure 2. TYRN station locations. Stations surround the release point of the 1999 rockfall events (shown as the pink area on the rock face), so that sources from the release point can be well located. The feducial explosion source near staion UE is also shown. 


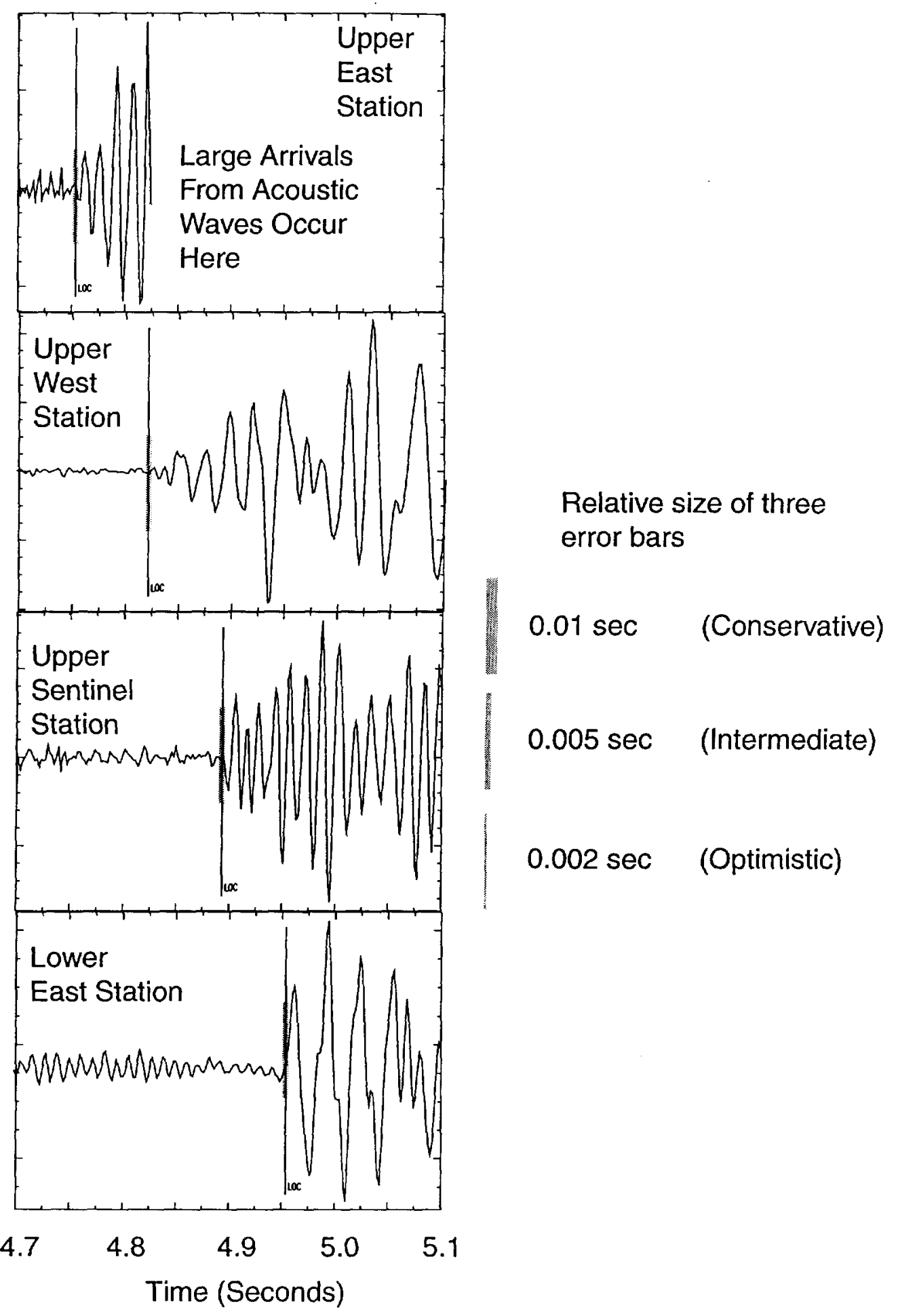

Figure 3 Recorded P-waves from a fiducial source. Arrival times are used to estimate P-wave velocity. The source was about $50 \mathrm{~m}$ from the Upper East Station. Gray bars centered on P-wave picks show the estimated picking uncertainty of 0.005 seconds. For comparison, examples of pick-time uncertainties are shown to the left. 


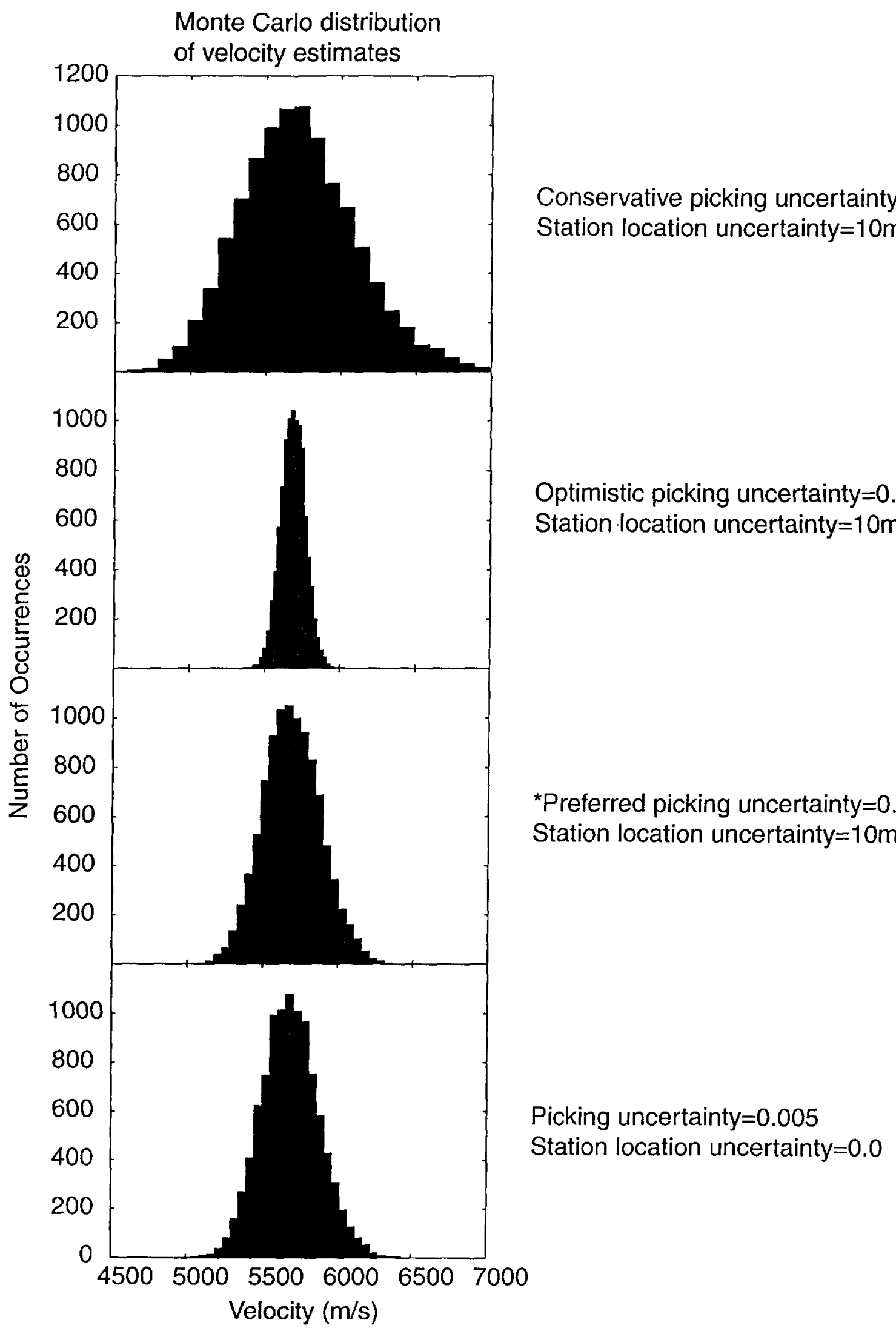

Figure 4. Distribution of velocity estimates given various picking and station location uncertainties. Uncertainty in station location is found to be negligible compared to picking uncertainty. If an optimistic picking uncertainty is chosen, then velocity can be tightly constrained. If a conservative estimate of picking uncertainty is chosen, then velocity is poorly constrained. We prefer an intermediate value for picking uncertainty, leading to a velocity estimate of 5.68 $\mathrm{km} / \mathrm{s} \pm 0.2 \mathrm{~km} / \mathrm{s}$ 
a)

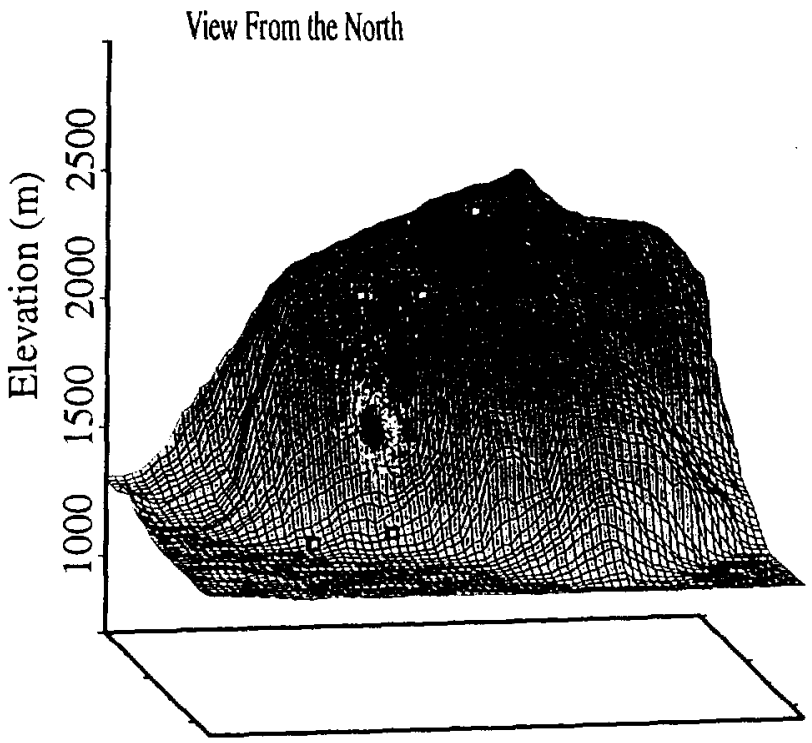

View From the East

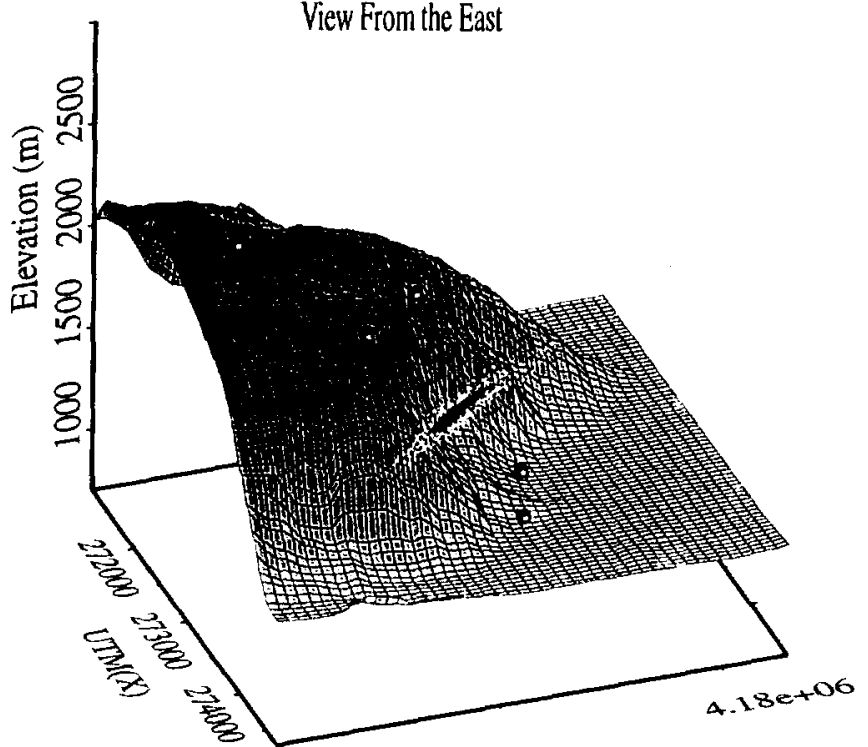

Realizations of locations using $P$-wave arrivals with picking uncertainty of 0.01 second .78 se+o6

Realizations of locations using $P$-wave arrivals with picking uncertainty of 0.005 second

Realizations of locations using $P$-wave arivals with picking uncertainty of 0.002 second

Seismic Stations

b)

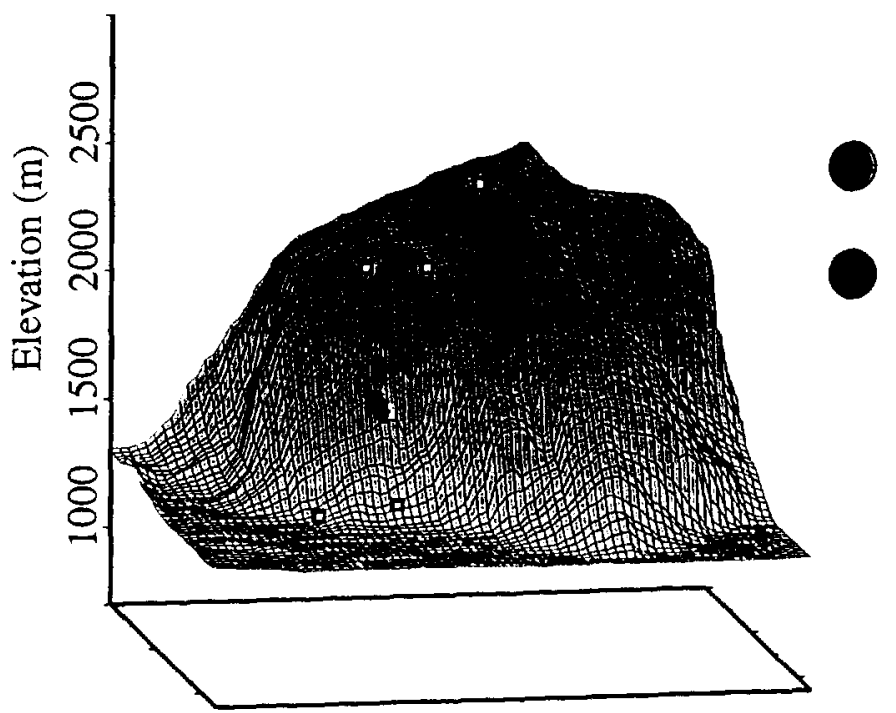

Realizations of locations using known P-wave Velocity $(5.68 \mathrm{~km} / \mathrm{s})$

Realizations of locations using P-wave velocity of $5.38 \mathrm{~km} / \mathrm{s}$ )

Figure 5. a) Test of location precision using synthetic data. The arrival times of $P$-waves are calculated for a hypothetical event. Random noise is added to the arrivals, and the event is re-located. The process of adding noise and re-locating is repeated one thousand times to give an estimate of location precision in the presence of noise. Three noise variances are tested: $0.01(\mathrm{~s}), 0.005(\mathrm{~s})$, and 0.002 (s). These variances represent conservative, intermediate, and optimistic arrival uncertainties, respectively. The true location of the synthetic event is in the center of the red (smallest) cluster. Note that mislocation often occurs perpendicular to the clif lace. Therefore, constraining the location to occur on the rock face would aid in precision. See text for further discussion.

b) A test of location accuracy is accomplished by using using one velocity to generate synthetic data and another velocity model to locate the events. In this case, a velocity of $5.68 \mathrm{~km} / \mathrm{s}$ is used to generate the synthetic arrivals and $5.38 \mathrm{~km} / \mathrm{s}$ is used to locate the events. A low picking uncertainty of 0.002 (s) is used so that changes in location can be seen. This test shows that location accuracy is somewhat effect by velocity model inaccuracies, but the picking uncertainty is by far the more important parameter. 


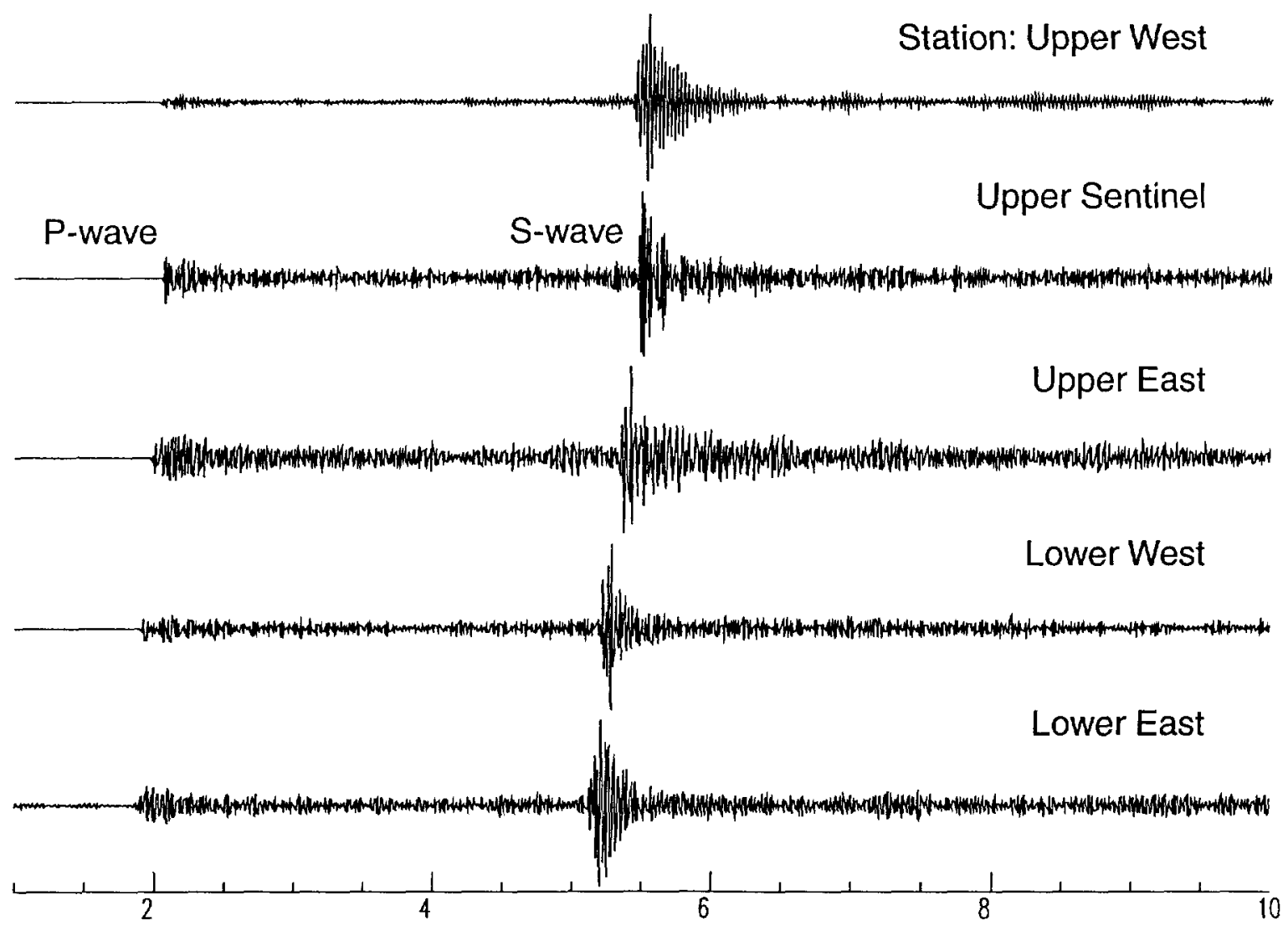

Time (seconds)

Figure 6. Event from Mammoth Lakes region recorded on the TYRN. The difference between the S-wave and P-wave arrival suggest that the event is about $27 \mathrm{~km}$ from the network. Relative timing of $P$-wave arrivals suggests that the source is roughtly east of the network. Similar events were observed 5 to 6 times per day. Although some days were significanly more active. 
a) 3-component recording of suspect event at station UE
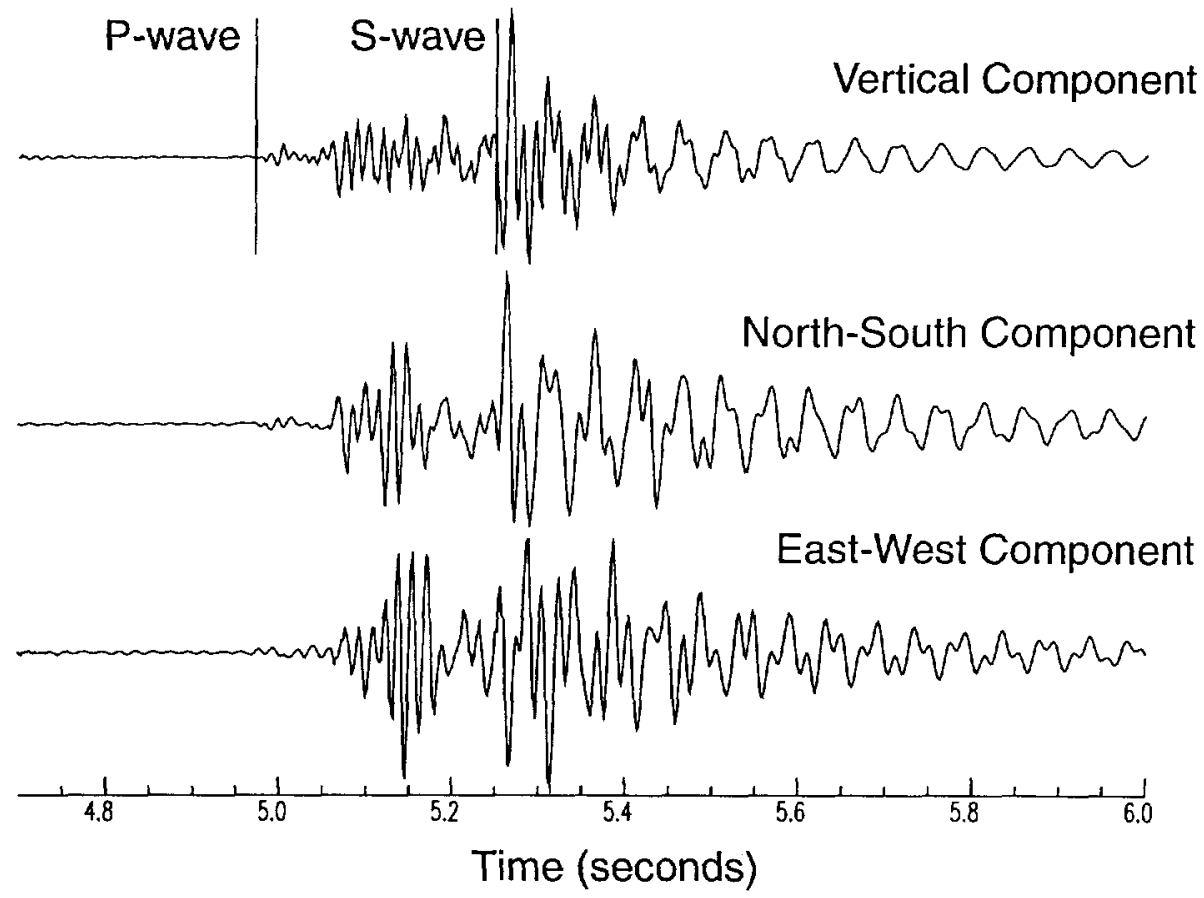

b) Vertical-Component recordings of suspect event at operating TYRN station

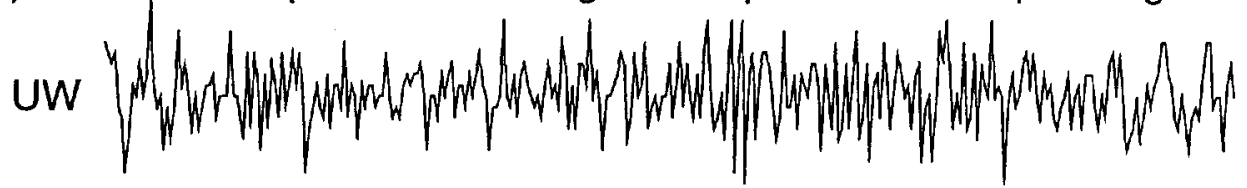

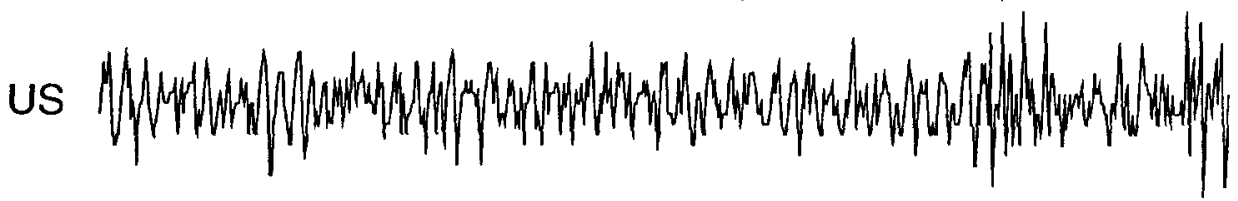

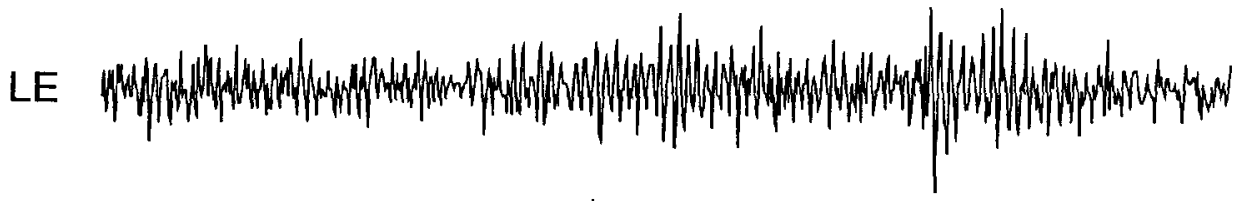

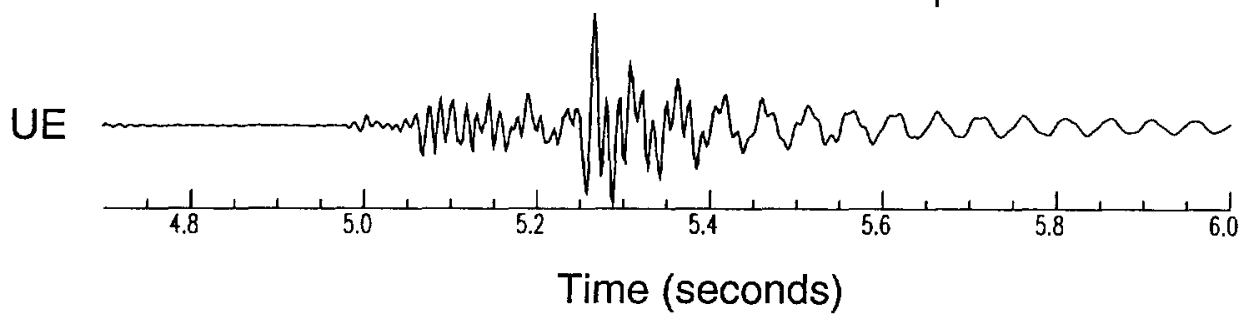

Figure 7. Recordings of a suspect event. a) 3-component recordings of a suspect event at TYRN station UE. The presence of a strong S-wave, difference between S-wave arrival and $\mathrm{P}$-wave arrival, and the lower frequency surface wave (ringing at the tail of the seismogram) are suggest a near-surface, shear-dislocation event that is about $2 \mathrm{~km}$ from the station. All of these attributes are expected for a rock cracking event associated with rock fall. b) Vertical component recordings of the event in a) at all of the operating TYRN stations. Amplitude is normalized by trace. Detections at stations other than UE were not present, precluding an estimate of event location. 